\title{
РОБОТА СИНХРОННОГО ГЕНЕРАТОРА $З$ ПОСТІЙНИМИ МАГНІТАМИ ПРИ ПІДМАГНІЧУВАННІ СТОРОННЬОЮ ЕМНІСТЮ
}

\author{
І.Я. Коваленко, асистент, аспірант
}

Національний технічний університет України «Київський політехнічний інститут ім. Ігоря Сікорського», 03056, пр-т. Перемоги, 37, м. Київ, Україна. Інститут відновлюваної енергетики НАН України, 02094, вул. Гната Хоткевича, 20А, м. Київ, Україна.

Вітроенергетика є екологічно чистим та ефективним засобом перетворення механічної енергї вітру на електричну. Вітроагрегати продовжують активно використовуватись до сього часу. Разом з тим проводяться активні роботи 3 вдосконалення вітрогенерувальних комплексів та підвищення ефективності перетворення енергї вітру на електричну. Одним зі способів підвищення ефективності перетворення енергї вітру на електричну є підмагнічування електрогенератора з постійними магнітами сторонньою статичною ємністю. Розроблено математичну модель для оцінки величини ємності, яку необхідно приєднати до обмотки статора електрогенератора, залежно від ряду умов: величини та характеру навантаження; параметрів електрогенератора; підвищення величини напруги на затискачах; підвищення активноі потужності на виході електрогенератора. За результатами розрахунків отримано вираз, щэо дозволяє оцінити необхідну величину ємності при чисто активному навантаженні.

Для діапазону потужності електрогенератора, щэо досліджувався, від нуля до номінального значення, величина ємності, яку необхідно приєднати до обмотки якоря електрогенератора з постійними магнітами становить 4,3-32,1 мкФ, щэо дає змогу забезпечити напругу на затискачах генератора близько номінальної з похибкою $\pm 5 \%$. При використанні додатковоі підмагнічувальної ємності для підвищення активної потужності генератора спостерігається ї̈ приріст на рівні 10-15\%. Результати розрахунку необхідної величини сторонньої ємності генератора підтверджують адекватність розробленої моделі та достовірність отриманих результатів, щзо дозволяє використовувати ичю модель для подальших досліджень та оцінки ефективності методів і засобів підвищення ефективності перетворення енергії вітру. Бібл. 7, табл. 3 , рис. 5.

Ключові слова: вітроустановка, синхронний генератор, підмагнічувальна ємність, постійні магніти.

\section{OPERATION OF THE SYNCHRONOUS GENERATOR WITH PERMANENT MAGNETS DURING THE MAGNETIZATION OF A SIDE CAPACITY}

\author{
I. Kovalenko, assistant, PhD student \\ National Technical University of Ukraine «Igor Sikorsky Kyiv Polytechnic Institute», \\ 03056, 37 Peremohy Av., Kyiv, Ukraine. \\ Institute of Renewable Energy of NAS of Ukraine, \\ 02094, 20A, Hnat Khotkevich Str., Kyiv, Ukraine
}

Wind energy is an environmentally friendly and efficient means of converting mechanical wind energy into electricity. Wind turbines continue to be actively used to this day. At the same time, active work is being done to improve wind generating complexes and increase the efficiency of converting wind energy into electricity. One of the ways to increase the efficiency of conversion of wind energy into electricity is to magnetize the generator with permanent magnets by a third-party static capacity. A mathematical model has been developed to estimate the value of the capacitance that must be connected to the stator winding of the generator depending on a number of conditions: the size and nature of the load; parameters of the electric generator; increasing the voltage on the clamps; increasing the active power at the output of the generator. According to the results of the calculations, an expression is obtained that allows to estimate the required value of the capacity at a purely active load. For the power range of the electric generator from 0 to $\approx P u$ the value of capacity which needs to be connected to a winding of an armature of the electric generator with permanent magnets makes $4,3-32,1 \mathrm{uF}$. This provides a voltage at the terminals of the generator $\approx U n$ with an error of $\pm 5 \%$. When using an additional magnetizing capacity to increase the active power of the generator, there is an increase in power at the level of 10-15\%. This is due to the increase in voltage at the generator terminals. 
The results of calculating the required value of the external capacity of the generator confirm the adequacy of the developed model and the reliability of the results, which allows to use this model for further research and evaluation of methods and means to improve wind energy conversion efficiency. Bibl. 7, table 3, fig. 5.

Keywords: wind turbine, synchronous generator, magnetizing capacity, permanent magnets.

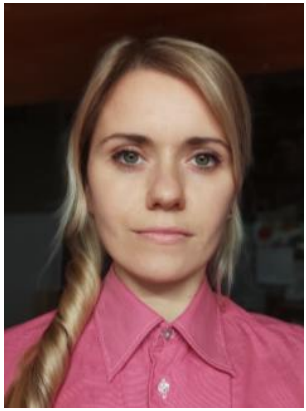

І.Я. Коваленко I Kovalenko
Відомості про автора: асистентка кафедри відновлюваних джерел енергії

Національного технічного університету

України «Київський політехнічний інститут імені Ігоря Сікорського», аспірантка

Освіта: Національний технічний університет України «Київський політехнічний інститут імені Ігоря Сікорського». Спеціальність: нетрадиційні джерела енергії

Наукова сфера: відновлювана енергетика Публікації: 8

ORCID: 0000-0003-1097-2041

Контакии: тел./факс: +38(097)939-96-73

e-mail: 2048141@ukr.net
Author information: assistant of the Department of Renewable Energy Sources of the National Technical University of Ukraine "Kyiv Polytechnic Institute named after Igor Sikorsky", PhD student

Education: National Technical University of Ukraine "Kyiv Polytechnic Institute named after Igor Sikorsky". Specialty - non-traditional energy sources

Research area: renewable energy

Publications: 8

ORCID: 0000-0003-1097-2041

Contacts: tel./fax: + 38(097)939-96-73

e-mail: 2048141@ukr.net

Перелік використаних позначень та скорочень:

$\mathrm{E}_{\delta}$ - електрорушійна сила, індукована в обмотці якоря основним магнітним потоком;

$\mathrm{I}_{1}, \mathrm{U}_{1}$ - струм та напруга обмотки якоря;

$\mathrm{R}_{1}, \mathrm{X}_{1}$ - активний та індуктивний опір розсіювання обмотки якоря;

$\mathrm{R}_{\mathrm{H}}, \mathrm{X}_{\mathrm{H}}-$ активний та індуктивний опір навантаження;

Вступ. На сьогодні синхронні генератори 3 постійними магнітами (СГПМ) становлять основу автономних генераторів для традиційних i нетрадиційних комплексів та систем перетворення механічної енергії вітру на електричну. Переважною задачею таких систем $€$ стабілізація вихідних параметрів та максимально ефективне перетворення енергії вітрового потоку на електричну. Одним зі способів стабілізації вихідних параметрів $€$ підмагнічування електрогенератора сторонньою ємністю. Однак у цей час питанню щодо розрахунку доцільної величини ємності для того чи іншого типу генератора приділяється недостатньо уваги.

Постановка завдання. Мета роботи полягає в розробці математичної моделі, що дозволяє отримати необхідну величину розрахункової ємності для впливу на ефективне перетворення механічної енергії вітрового потоку на електричну.
$\mathrm{I}_{\mathrm{c}}, \mathrm{X}_{\mathrm{c}}$ - струм в колі конденсатора та його опір;

$\mathrm{F}$ - частота процесів в обмотці статора;

$\mathrm{X}_{\mathrm{m}}$ - індуктивний опір взаємоіндукції.

Результати досліджень. За основу взято електрогенератор конструкції, параметри та характеристики якого описані в роботах вітчизняних авторів $[1,2]$. Для оцінки статичних характеристик системи вітроагрегателектрогенератор із постійними магнітами доцільно модифікувати розроблену раніше математичну модель в середовищі MATLABSimulink.

Для розрахунку величини ємності, яку необхідно приєднати до обмотки якоря СГПМ, використана заступна схема, що наведена на рис. 1 [3]. У разі, коли СГПМ працюе в автономному режимі, напруга та іiі частота, визначаються швидкістю обертання привідного рушія (ротора вітроустановки), величиною приєднаної до обмотки якоря ємності та величиною навантаження генератора. 


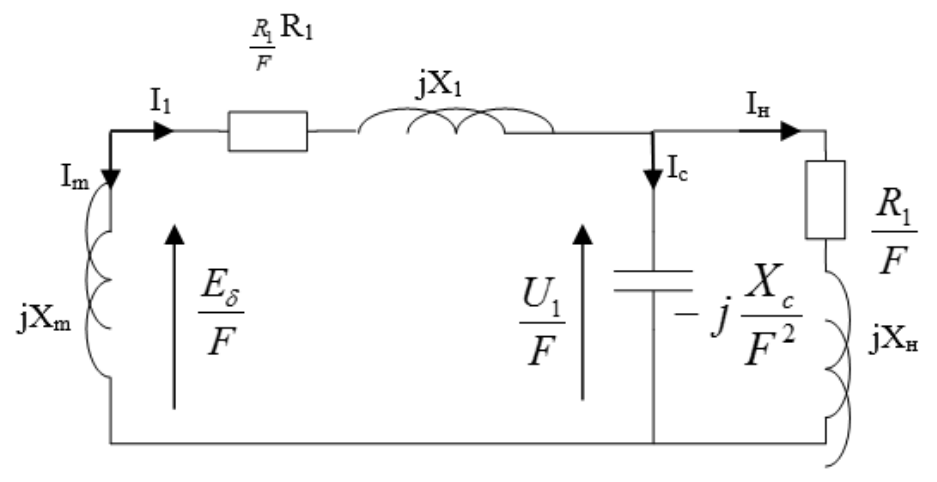

Рис. 1. Заступна схема СГПМ

Fig. 1. Substitute scheme SGPM

На рис. 1 використані позначення: $\mathrm{E}_{\delta}-\mathrm{EPC}$ (електрорушійна сила), індукована в обмотці якоря основним магнітним потоком; $\mathrm{I}_{1}, \mathrm{U}_{1}$ - струм i напруга обмотки якоря; $\mathrm{R}_{1}, \mathrm{X}_{1}$ - активний та індуктивний опір розсіювання обмотки якоря; $\mathrm{R}_{\mathrm{H}}$, $\mathrm{X}_{\mathrm{H}}$ - активний та індуктивний опір навантаження; $\mathrm{I}_{\mathrm{c}}, \mathrm{X}_{\mathrm{c}}$ - струм в колі конденсатора та його опір; $\mathrm{F}$ - частота струму й напруги в обмотці статора; $\mathrm{X}_{\mathrm{m}}$ - індуктивний опір взаємоіндукції, що $\epsilon$ еквівалентним магнітним опором взаємоіндукції між потоком постійних магнітів та обмоткою якоря.

Всі індуктивні опори заступної схеми приведені до номінальної частоти обмотки статора $\mathrm{F}$ та відносної частоти обертання ротора генератора $\omega$. Також необхідно враховувати, що індуктивний опір намагнічування $\mathrm{X}_{\mathrm{m}} \epsilon$ змінною величиною, яка залежить від величини $\mathrm{E}_{\delta}$, при номінальній частоті F. Цей процес залежить від параметрів електротехнічної сталі та описується кривою намагнічування, яка математично описується кубічним рівнянням [4-6]:
$\frac{E_{\delta}}{F}\left(X_{m}\right)=k_{3} \cdot X_{m}^{3}+k_{2} \cdot X_{m}^{2}+k_{1} \cdot X_{m}+k_{0}$

$\mathrm{V}$ рівнянні (1) коефіцієнти $\mathrm{k}_{0}, \mathrm{k}_{1}, \mathrm{k}_{2}$ та $\mathrm{k}_{3}$ обчислюються у системі відносних одиниць за відомими алгоритмами [4-6].

Для зручності обчислення необхідної величини розрахункової ємності СГПМ всі опори заступної схеми зводяться до трьох послідовно 3'єднаних опорів $Z_{1}, Z_{2}$ та $Z_{3}$ :

$$
\begin{gathered}
Z_{1}=\frac{R_{1}}{F}+j X_{1} \\
Z_{2}=j X_{m} \\
Z_{3}=\frac{\left(-\frac{j X_{c}}{F^{2}}\right)\left(\frac{R_{u}}{F}+j X_{u}\right)}{\left(-\frac{j X_{c}}{F^{2}}\right)+\left(\frac{R_{u}}{F}+j X_{u}\right)}
\end{gathered}
$$

Рівняння (2), (3) та (4) відповідають спрощеній заступній схемі, що наведена на рис. 2 .

$\mathrm{Z}_{1}$

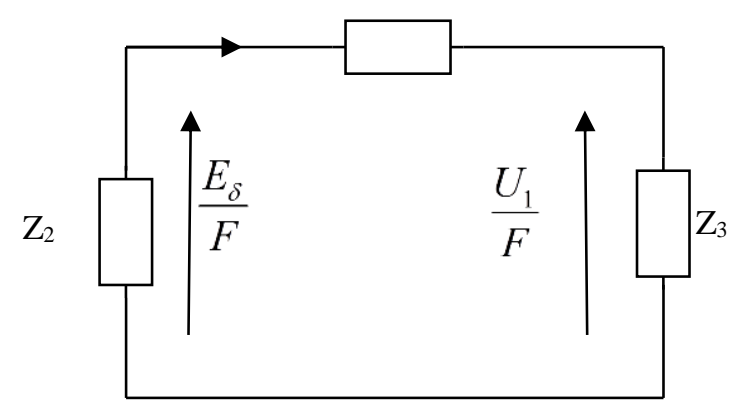

Рис. 2. Спрощена заступна схема СГПМ

Fig. 2. Simpli fied substitution scheme SGPM 
Сумарний опір спрощеної заступної схеми СГПМ (див. рис. 2), відповідно до першого закону Кіргофа, описується таким рівнянням:

$$
\begin{gathered}
\mathrm{Z}_{\mathrm{T}}=\mathrm{Z}_{1}+\mathrm{Z}_{2}+\mathrm{Z}_{3} \\
\mathrm{I}_{1} \cdot \mathrm{Z}_{\mathrm{T}}=0
\end{gathered}
$$

Після декількох математичних перетворень реальна та уявна частини повного опору $\mathrm{Z}_{\mathrm{T}}$ розкладаються у систему 3 двох поліноміальних виразів:

$$
\left\{\begin{array}{l}
f_{1}=\operatorname{Im}\left(Z_{T}\right)=0 \\
f_{2}=\operatorname{Re}\left(Z_{T}\right)=0
\end{array}\right.
$$

Функції в системі рівнянь (6) описуються такими виразами:

$$
\begin{aligned}
& f 1=a_{1} F+a_{2} F^{2}+a_{3} F^{3}+a_{4} F^{4}+a_{5} F^{5} \\
& f 2=b_{0}+b_{1} F^{1}+b_{2} F^{2}+b_{3} F^{3}+b_{4} F^{4},
\end{aligned}
$$

де коефіцієнти в рівнянні (6) $\mathrm{a}_{1}-\mathrm{a}_{5} \mathrm{Ta}_{\mathrm{b}}-\mathrm{b}_{4}$ [4-6]:

$$
\begin{gathered}
a_{1}=\varepsilon_{6} X_{C}^{2}-a_{6} R_{t}^{2} ; \\
a_{2}=-2 \varepsilon_{3} X_{C}^{2}+R_{H}^{2} a_{2} X_{C} ; \\
a_{3}=\varepsilon_{3} X_{C}^{2}-\varepsilon_{4} X_{C}+\varepsilon_{5} ; \\
a_{4}=2\left(-\varepsilon_{1} X_{C}-R_{H}^{2} a_{1}\right) ; a_{5}=\varepsilon_{1} X_{C}+\varepsilon_{2} ; \\
b_{0}=\beta_{4} a_{5} X_{C}^{2} ; b_{1}=-\delta_{1} X_{C}^{2} ; \\
b_{2}=\left(R_{H} a_{2}+\delta_{2}\right) X_{C}^{2}+\left(2 X_{H} \delta_{3}\right) X_{C}+\beta_{5} a_{4} ; \\
b_{3}=\left(2 X_{H} \delta_{4}\right) X_{C}-R_{H}^{2} \delta_{4} ; b_{4}=-2 \delta_{5} X_{C}
\end{gathered}
$$

Значення всіх коефіцієнтів $\mathrm{a}_{1}-\mathrm{a}_{6}, \varepsilon_{1}-\varepsilon_{6}, \beta_{1}-\beta_{5}$ та $\delta_{1}-\delta_{5}$ визначаються за виразами:

$$
\begin{gathered}
a_{1}=X_{m}^{2} X_{1} ; a_{2}=X_{m}^{2} ; a_{3}=R_{1}^{2}\left(1+X_{1}\right) ; \\
a_{4}=R_{1}^{2}\left(X_{m}+X_{1}\right) ; a_{5}=R_{H}^{2}\left(X_{m}+X_{1}\right) ; \\
a_{6}=\left(R_{H}^{2}+X_{1}\right) ; \\
\varepsilon_{1}=\left(-a_{2}-2 a_{1} X_{H}\right) ; \varepsilon_{2}=\left(a_{1} X_{H}^{2}+R_{H}^{2} a_{1}\right) ; \\
\varepsilon_{3}=a_{2} X_{H}+a_{1} ; \varepsilon_{4}=\left[a_{6} X_{H}^{2}+\left(2 a_{1} X_{H}\right)+R_{H}^{2} a_{2}\right] ; \\
\varepsilon_{5}=R_{H}^{2}\left(a_{4}+a_{1}\right) ; \varepsilon_{6}=\left(a_{6} X_{H}+a_{1}\right) ; \\
\beta_{1}=R_{H} X_{m}^{2} ; \beta_{2}=R_{1} a_{2} ; \beta_{3}=R_{H}^{2} R_{1} ; \\
\beta_{4}=R_{1}^{2} R_{H} ; \beta_{5}=R_{H}+R_{1} ; \\
\delta_{1}=\left(2 a_{2} \beta_{5}+\beta_{1}\right) ; \delta_{2}=\left(\beta_{1}+\beta_{2}\right) ; \\
\delta_{3}=\left(\beta_{2}+\beta_{3}\right) ; \\
\delta_{4}=\left(\beta_{1}+2 \beta_{2}\right) ; \delta_{5}=\left(\beta_{1}+\beta_{2} X_{H}\right) .
\end{gathered}
$$

Вираз (6) необхідно розв'язувати для випадку, коли відомі значення індуктивності взаємоіндукції $\mathrm{X}_{\mathrm{m}}$ та невідомих значень опору додаткової ємності $\mathrm{X}_{\mathrm{c}}$ при частоті струмів та напруги в обмотці якоря $F$. Враховуючи вищевикладене, отримаємо такий вираз:

$$
f(X)=0 \text {, }
$$

де

$$
\begin{aligned}
& f=\left[\begin{array}{ll}
f_{1} & f_{2}
\end{array}\right]^{T} \\
& X=\left[\begin{array}{ll}
X_{C} & F
\end{array}\right]^{T}
\end{aligned}
$$

Для розв'язку системи рівнянь (6) використовується алгоритм Ньютона - Рафсона. Даний метод $\epsilon$ найбільш простим та ефективним порівняно з іншими методами [7].

Для визначення необхідної величини ємності скористаємося спрощеною заступною схемою (див. рис. 2), згідно з якою напруга на затискачах обмотки статора СГПМ визначається як

$$
U_{1}=\frac{Z_{3}}{Z_{3}+Z_{1}} E_{\delta}
$$

Якщо прийняти за основу припущення, що напруга на затискачах обмотки статора генератора повинна бути номінальною, отримаємо систему рівнянь:

$$
\left\{\begin{array}{l}
f_{1}=\operatorname{Im}\left(Z_{T}\right)=0 \\
f_{2}=\operatorname{Re}\left(Z_{T}\right)=0 \\
f_{3}=\left|\frac{Z_{3}}{Z_{3}+Z_{1}}\right| \cdot E_{\delta}-U_{1 H}=0
\end{array}\right.
$$

Для заданого режиму роботи та навантаження обмотки статора напруга обмотки статора залежить від величини ємності конденсатора $\mathrm{X}_{\mathrm{c}}$ та від величини наведеної ЕРС в обмотці якоря потоком постійних магнітів $\left(\mathrm{E}_{\delta}\right)$.

Для оцінки залежності ємності конденсатора С, що приєднується до затискачів обмотки якоря генератора, прийняті такі припущення:

- швидкість вітру приймається постійною; 
- швидкість обертання ротора генератора $n$, a отже, і частота $f$ EPC та струмів генератора приймається постійною;

- для спрощення розрахунків приймається чисто активне навантаження генератора: $Z_{\mathrm{H}}=\mathrm{R}_{\mathrm{H}}$;

- напруга на затискачах генератора та його параметри приймаються постійними.

Враховуючи згадані вище припущення, умовою для розрахунку ємності в разі шунтового приєднання буде:

$$
\left|\frac{Z_{3}}{Z_{3}+Z_{1}}\right| \cdot E_{\delta}-U_{1 \mu}=0
$$

Опори $Z_{1}$ та $Z_{3}$ визначаються в такий спосіб:

$$
\begin{aligned}
& Z_{1}=R_{1}+j X_{1} \\
& Z_{3}=-\frac{j X_{C} R_{H}}{R_{H}-j X_{C}}
\end{aligned}
$$

Після перетворень отримуємо вираз:

$$
\frac{Z_{3}}{Z_{1}+Z_{3}}=\frac{-j X_{C} R_{u}}{-j X_{C} R_{u}+R_{1} R_{u}-j X_{C} R_{1}+j X_{1} R_{1}+X_{1} X_{C}}
$$

Підставивши вираз (12) у вираз (10), отримаємо:

$$
X_{C}=\frac{U_{1} R_{1}\left(R_{H}+j X_{1}\right)}{\left[U_{1} X_{1}+j\left(R_{H} U_{1}+R_{1} U_{1}-R_{H} E_{\delta}\right)\right]}
$$

3 виразу (13) визначається необхідна величина ємності конденсатора на одну фазу шляхом перетворення. Для цього необхідно визначити модуль комплексного числа (13). Після декількох математичних перетворень вираз (13) набуває такого вигляду:

$$
X_{C}=\frac{U_{1}^{2} X_{1} R_{1} R_{H}+U_{1} R_{1} X_{1} a}{U_{1}^{2} X_{1}^{2}+a^{2}}+j \frac{U_{1}^{2} X_{1}^{2}-U_{1} R_{1} R_{H} a}{U_{1}^{2} X_{1}^{2}+a^{2}}
$$

3 виразу (14) визначається модуль комплексного числа Хc, з якого далі визначається величина додаткової ємності:

$$
X_{C}=\sqrt{\left(\frac{U_{1}^{2} X_{1} R_{1} R_{n}+U_{1} R_{1} X_{1} a}{U_{1}^{2} X_{1}^{2}+a^{2}}\right)^{2}+\left(\frac{U_{1}^{2} X_{1}^{2}-U_{1} R_{1} R_{n} a}{U_{1}^{2} X_{1}^{2}+a^{2}}\right)^{2}},
$$

де $a=R_{H} U_{1}+R_{1} U_{1}-R_{H} E_{\delta}$

3 виразу (15) визначається величина додаткової підмагнічувальної ємності згідно 3 виразом:

$$
C=\frac{1}{2 \pi f X_{C}}
$$

Згідно 3 виразом (15) величина ємності залежить від параметрів обмотки якоря електрогенератора, величини взаємоіндукції, характеру та величини навантаження. Підставимо параметри досліджуваного генератора та визначимо величину розрахункової ємності при номінальному навантаженні. Параметри генератора та навантаження наведено в табл. 1.

Таблиця 1. Параметри генератора та навантаження

Table 1. Generator parameters and load parameters

\begin{tabular}{|c|c|c|}
\hline Параметр & Значення & Одиниці виміру \\
\hline $\mathrm{R} 1$ & 8,8 & Ом \\
\hline $\mathrm{X} 1$ & 6,9 & Ом \\
\hline $\mathrm{U} 1$ & 24 & В \\
\hline $\mathrm{RH}$ & 33,0 & Ом \\
\hline $\mathrm{E} \delta$ & 26,4 & $\mathrm{~B}$ \\
\hline
\end{tabular}




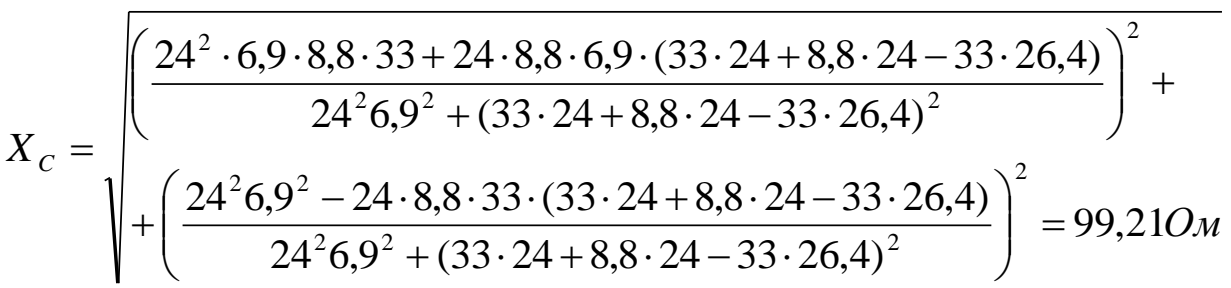

$$
\begin{aligned}
& C=\frac{1}{2 \pi f X_{C}}=32,1 \cdot 10^{-6} \Phi
\end{aligned}
$$

При постійній швидкості обертання ротора вітроустановки та при заданій величині навантаження генератора розраховується значення ємності, необхідне для підтримки заданої величини напруги. Задаємось відхиленням напруги електрогенератора на його виході в межах $+5 \%,-5 \%$ від номінальної. При цьому рівняння (9) необхідно розв'язувати за незмінних значень вихідної напруги $U_{\max }$ та $U_{\min }$. Кожна розрахункова величина ємності дозволяє СГПМ працювати у фіксованому діапазоні потужності в межах заданої похибки за вихідною напругою. Розрахункові значення ємності, що забезпечують максимальне значення потужності при зміні навантаження та постійній швидкості вітру 5 м/с, наведені в табл. 2.

Таблиця 2. Значення додаткової ємності для підтримки $\mathrm{U}_{1} \approx \mathrm{U}_{\mathrm{H}}+5 \%,-5 \%$

Table 2. The value of the additional capacity to support $\mathrm{U} 1 \approx \mathrm{Un}+5 \%,-5 \%$

\begin{tabular}{|c|c|c|c|c|c|}
\hline $\begin{array}{c}\text { Діапазон зміни } \\
\text { потужності }\end{array}$ & $0-\mathrm{P}_{0}$ & $\mathrm{P}_{0}-\mathrm{P}_{1}$ & $\mathrm{P}_{1}-\mathrm{P}_{2}$ & $\mathrm{P}_{3}-\mathrm{P}_{4}$ & $\mathrm{P}_{5}-\mathrm{P}_{6}$ \\
\hline Діапазон потужності, Вт & $0-17$ & $17-36$ & $36-58$ & $58-77$ & $77-86$ \\
\hline $\begin{array}{c}\text { Смність збудження } \\
\text { (аналітичний метод), мкФ }\end{array}$ & 4,3 & 8,9 & 15,7 & 26,3 & 32,1 \\
\hline $\begin{array}{c}\text { Смність збудження } \\
\text { (моделювання в } \\
\text { МАТLАВ-Simulink), мкФ }\end{array}$ & 4,056 & 8,72 & 16,5 & 27,17 & 30,68 \\
\hline
\end{tabular}

Отже, наведені методичні положення В табл. 3 наведені результати розрахунку дозволяють розрахувати доцільне значення величини ємності, що приєднуються до статора ємності конденсаторів, що приєднуються до генератора, при якій він віддає максимальну статора електрогенератора при постійній потужність за умови, що швидкість вітру швидкості вітру та постійному навантаженні. постійна, 4 м/с, i постійне навантаження, 33,0 Ом.

Таблиця 3. Залежність максимальної потужності СГПМ від додаткової ємності

Table 3. Dependence of the maximum power of SGPM on additional capacity

\begin{tabular}{|c|c|c|c|c|}
\hline С, мкФ & 0 & 11,3 & 30 & 100 \\
\hline Р, Вт & 42 & 52,5 & 50,3 & 30,82 \\
\hline
\end{tabular}

Для наочності дані табл. 2, подамо в графічному вигляді (рис. 3). 


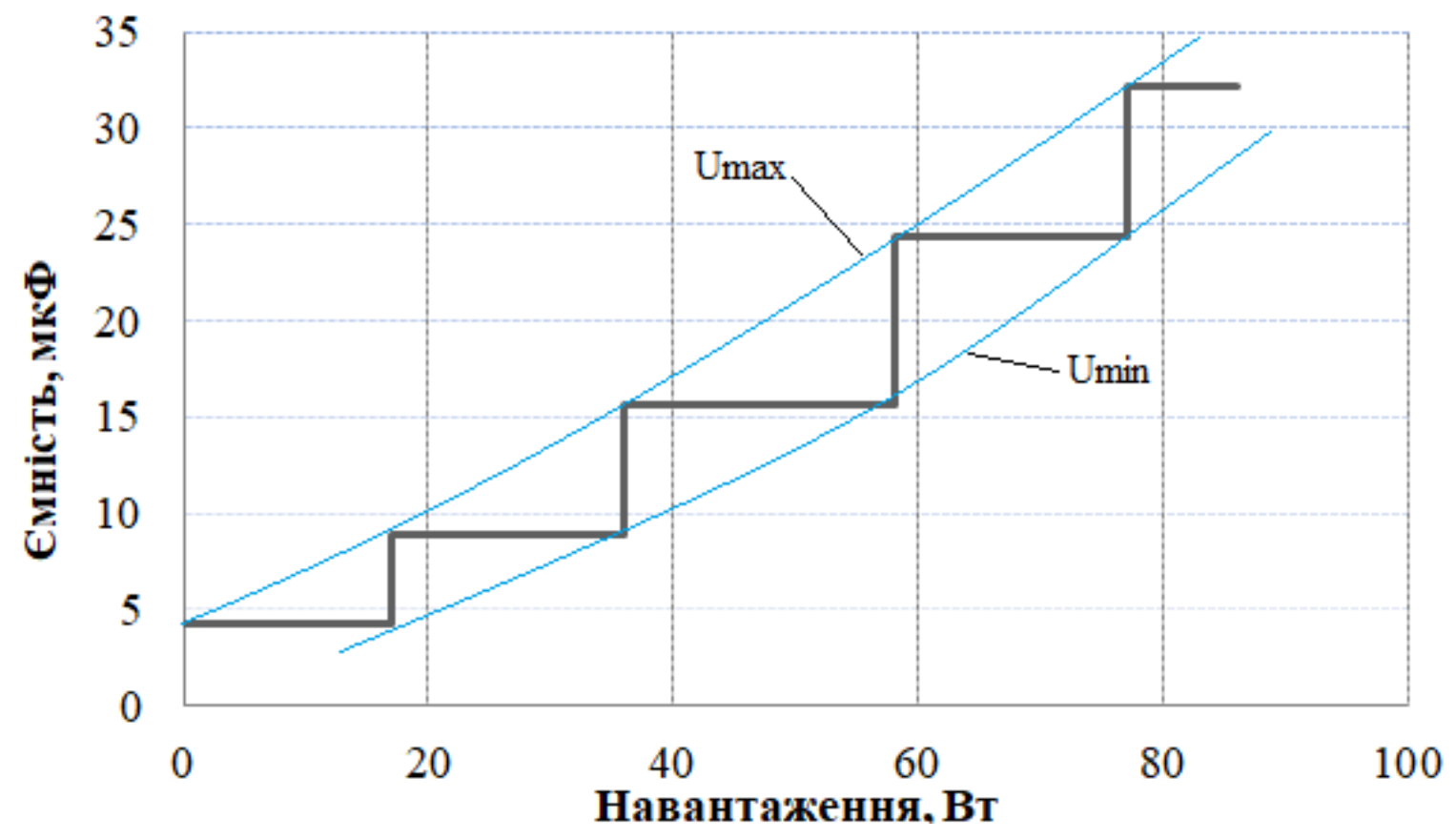

Рис. 3. Залежність смності від навантаження при постійній напрузі

Fig. 3. Dependence of capacity on load at constant voltage

В такому разі необхідне ступінчасте проаналізовано залежність вихідної напруги та регулювання вихідної напруги й потужності, що потужності досліджуваного генератора для значно здорожує та ускладнює систему. Для швидкості вітру 4 м/с. На рис. 4 наведена оцінки вихідної потужності СГПМ при залежність вихідної потужності досліджуваного підмагнічуванні сторонньою ємністю генератора при різних значеннях додаткової використовується розроблена та описана в ємності та постійної величини активного попередній роботі модель в системі MATLAB- навантаження.

Simulink [1]. 3 використанням цієї моделі

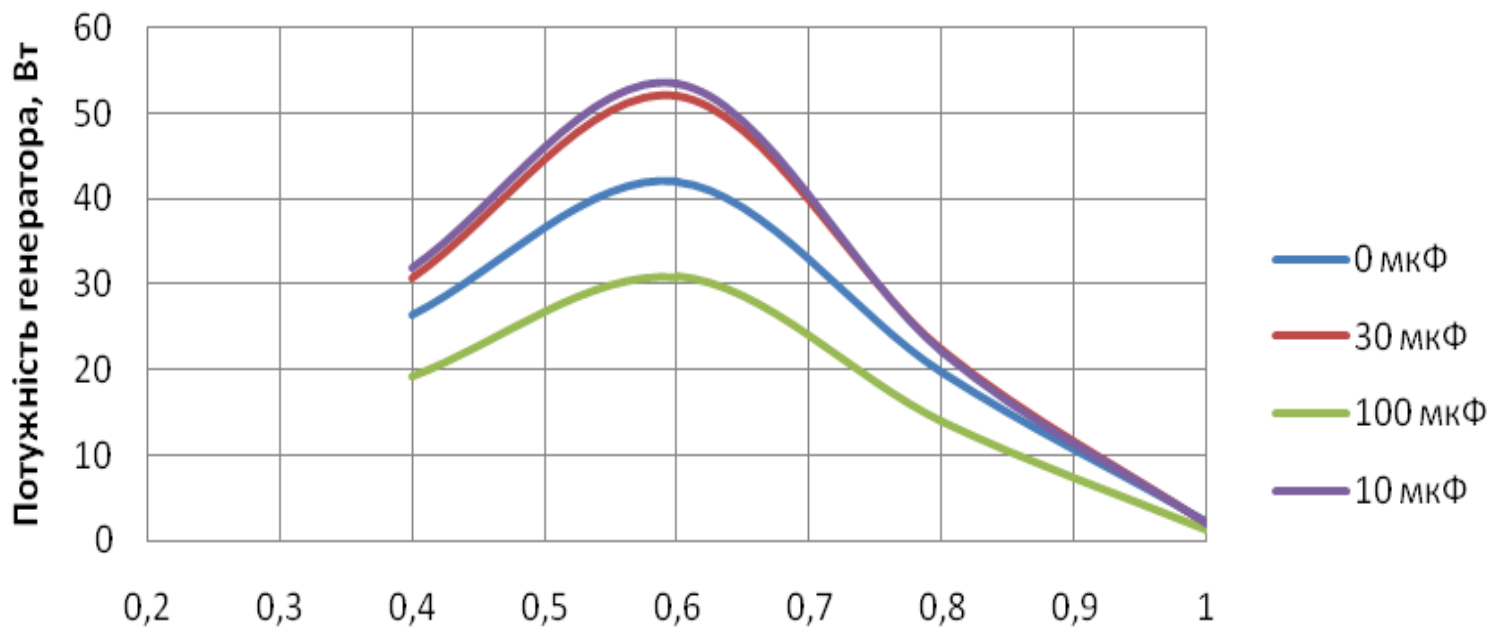

Швидкість обертання ротора, в.о.

Рис. 4. Залежність потужності СГПМ від швидкості обертання ротора

Fig. 4. Dependence of SGPM power on the rotor speed 
Для зручності швидкість обертання ротора подана у в.о. На рис. 4 показано, що максимальне значення потужності генератора, 52 Вт, досягається при значенні ємності 10 мкФ, подальше збільшення ємності понад 30 мкФ призводить до поступового зниження активної потужності до 30 Вт при значенні ємності 100 мФ. Зниження величини активної потужності при збільшення величини додаткової ємності пояснюється насиченням магнітної системи генератора та збільшенням активних втрат в обмотці якоря, а отже, і падінням ККД.

На рис. 5 наведено залежність напруги на виході генератора при постійному навантаженні 33,0 Ом.

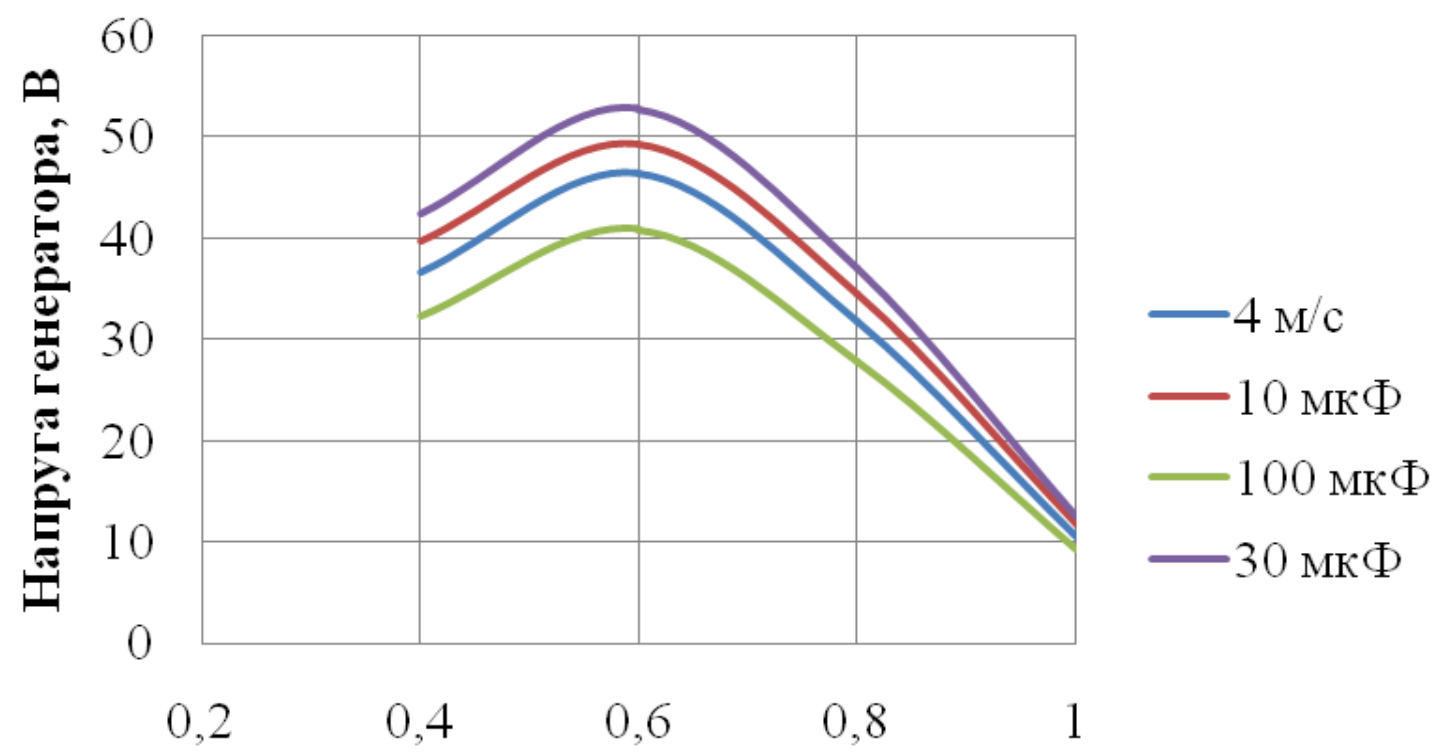

\section{Швидкість обертання ротора, в.о.}

Рис. 5. Залежність напруги генератора від швидкості обертання ротора

Fig. 5. Dependence of the generator voltage on the rotor speed

Максимальне значення напруги на виході генератора, $53 \mathrm{~B}, \quad$ спостерігається, коли приєднується підмагнічувальна ємність 30 мкФ, що відповідає заданому навантаженню. В разі приєднання ємності величиною в 10 мкФ напруга має дещо менше значення - 48 В. Це пояснюється тим, що при заданому навантаженні підмагнічувальної потужності конденсатора 10 мкФ не достатньо для компенсації розмагнічувальної реакції якоря. Подальше збільшення підмагнічувальної ємності не приводить до підвищення напруги, оскільки надлишок реактивної потужності перевантажує досліджуваний генератор 3 подальшим погіршенням всіх експлуатаційних характеристик.
Висновки. 1. Розроблено математичну модель для оцінки величини ємності конденсаторів для впливу на ефективне перетворення механічної енергії вітрового потоку на електричну. Встановлено, що величина ємності залежить від параметрів обмотки якоря електрогенератора, величини взаємоіндукції, характеру та величини навантаження. Для досліджуваного генератора значення ємності лежать в межах від 4,3-32,1 мкФ для чисто активного навантаження та для діапазону потужності 0-87 Вт.

2. За допомогою розробленої моделі в системі MATLAB-Simulink проведено оцінку впливу додаткової підмагнічувальної ємності на величину потужності та вихідної напруги генератора при зміні швидкості обертання ротора 
вітроагрегату та постійній швидкості вітру. Для швидкості вітру $4 \mathrm{~m} / \mathrm{c}$ при приєднанні ємності 10 мкФ спостерігається робота генератора при максимальній потужності в порівнянні із ємністю 30 мкФ та 100 мкФ. На відміну від ємності 30 мкФ i 100 мкФ, в разі приєднання ємності 10 мкФ для швидкості вітру $4 \mathrm{~m} / \mathrm{c}$ генератор працює 3 максимальною потужністю.

1. Головко В.М., Коваленко М.А., Коваленко І.Я. Математичне моделювання автономної вітроустановки 3 синхронним генератором магнітоелектричного типу. Відновлювана енергетика. Київ. 2020. № 4 (62). С. 31-39.

2. Головко В.М., Монахов С.А., Пономарьов О.I., Коваленко I.Я. Порівняння традиційного генератора із постійними магнітами 3 торцевим генератором із двосторонньою активною поверхнею для вітроустановок. Відновлювана енергетика. Київ. 2018. № 2 (53). С. 29-37.

3. Бисов А.A. Математическое описание синхронного двигателя с постоянными магнитами. Текст: непосредственный. Молодой ученый. 2014. № 21 (80). C. $104-108$

4. Haque M.H. Characteristics of a stand-alone induction generator in smallhydroelectric plants. Australasian Universities Power Engineering Conference AUPEC'08. December. 2008. Pp. 42-47.

5. Bajpai $P$., Dash $V$. Hybrid renewable energy systems for power generation instand-alone applications: a review. Renew Sustainable Energy Rev. 2012. № 16 (5). Pp. 2926-2939.

6. Chan T.F. Self excited induction generators driven by regulated and unregu-lated turbines. IEEE Trans Energy Convers. 1996. № 11 (2). Pp. 338-343.

7. Chermiti D., Khedher A. A new method voltage and frequency regulation of self excited induction generator operating in stand alone. WSEAS Trans Envi-ron Dev. 2014. № 10. Pp. 150-159.

\section{REFERENCES}

1. Holovko V.M., Kovalenko M.A., Kovalenko I.Ya. Matematuchne modeljyvannja avtonomnoyi vitroustanovky z synhronnum heneratorom mahnitoelektrychnoho typu. [Mathematical simulation of autonomous wind installation with synchronous magneto-electric type generator]. Vidnovluvana energetika. Kyiv. 2020. No. 4(62). C. 31-39. [in Ukrainian].

2. Holovko V.M., Monakhov Ye.A., Ponomarov O.I., Kovalenko I.Ya. Porivnyannya tradytsiynoho heneratora iz postiynymy mahnitamy $\mathrm{z}$ tortsevym heneratorom iz dvostoronnoyu aktyvnoyu poverkhneyu dlya vitroustanovok. [Comparison of a traditional generator with permanent magnets with an end generator with a double-sided active surface for wind turbines]. Vidnovluvana energetika. Kyiv. 2018. No. 2(53). Pp. 29-37. [in Ukrainian].

3. Bisov A.A. Matematicheskoye opisaniye sinhronnoho dvihatelja s postojannumi magnitami. [Mathematical description of a permanent magnet synchronous motor]. Molodoyuchonyy. 2014. No. 21(80). Pp. 104-108. [in Russian].

4. Haque M.H. Characteristics of a stand-alone induction generator in smallhydroelectric plants. Australasian Universities Power Engineering Conference AUPEC'08. December. 2008. Pp. 42-47.

5. Bajpai P., Dash V. Hybrid renewable energy systems for power generation instand-alone applications: a review. Renew Sustainable Energy Rev. 2012. No. 16(5). Pp. 2926-2939.

6. Chan T.F. Self excited induction generators driven by regulated and unregu-lated turbines. IEEE Trans Energy Convers. 1996. No. 11(2). Pp. 338-343.

7. Chermiti D., Khedher A. A new method voltage and frequency regulation of self excited induction generator operating in stand alone. WSEAS Trans Envi-ron Dev. 2014. No. 10. Pp. $150-159$. 